\title{
A CASE STUDY OF HYDRODYNAMIC AND MORPHOLOGICAL MODELING OF A RE-MIGRATING INLET
}

\author{
Soroush Sorourian ${ }^{1}$ and Babak Banijamali ${ }^{1}$
}

\begin{abstract}
The present paper tackles morphological modeling of a rare case of a re-migrating inlet to be used as the basis of a fishery port site selection study. The Tang inlet, located on the south-eastern shores of Iran, has so far been experiencing a cyclic migration with a return period of approximately a decade. In order to grasp the essence of the morphological behavior of the inlet, a two-fold site monitoring campaign was performed, consisting of a shoreline evolution study using aerial \& satellite imagery for the outside of the bay as well as a sedimentation pattern comparison based on past hydrographical survey results for the inside of the bay utilizing ArcGIS software. Subsequently, numerical modeling of the inlet comprising of nearshore wave transformation, tidal regime of the bay, one-line coastline evolution and two-dimensional sediment transport within the bay was carried out utilizing MIKE 21 package. Ebb channel switching from a westerly to an easterly orientation is deemed to occur due to self-suffocation as a result of the presence of an existing offshore rock formation, as well as the salient making potential of the rock system. On the other hand, the closure of the east-facing channel is mainly attributed to diffraction currents due to Monsoon southerly waves helped by sedimentation load from inside the bay system due to floods \& ebb currents.
\end{abstract}

Keywords: re-migrating inlet; numerical modeling; monitoring, one-line

\section{INTRODUCTION/SIGNIFICANCE OF STUDY}

The significant role of coastal inlets in nearshore hydrodynamic processes, particularly in regions with complex planforms is unanimously recognized around the world. Due to complexities of the physics of coastal inlets, proper prediction of sedimentation and shoaling in these areas represent a significant challenge. Nonetheless, a better understanding of interactions between tidal, waves and other hydrodynamic processes on one hand, and inlet sedimentology and morphology on the other, can lead to a more thorough coastal zone management and engineering design of the related facilities. The ensuing sedimentation patterns and inlet morphology including the ebb and flood deltas/channels are primarily associated with the delicate balance of the effects of tidal currents, nearshore wave energy and possibly ephemeral floods, perturbations of which may result in inlet or channel migration (Nummedal and Fischer 1978; Fitzgerald et al. 1984). The stability or migration of an inlet, in particular, is governed mainly by wave energy, littoral system as a principal sediment source, and tidal currents that carry sediment in or out of the inlet channel (Oertel 1988).

Tang inlet, located on the south-eastern shores of Iran on the northern shoreline of the Gulf of the Oman, provides a channel between the fairly narrow Tang bay and the Gulf of Oman (Fig. 1).

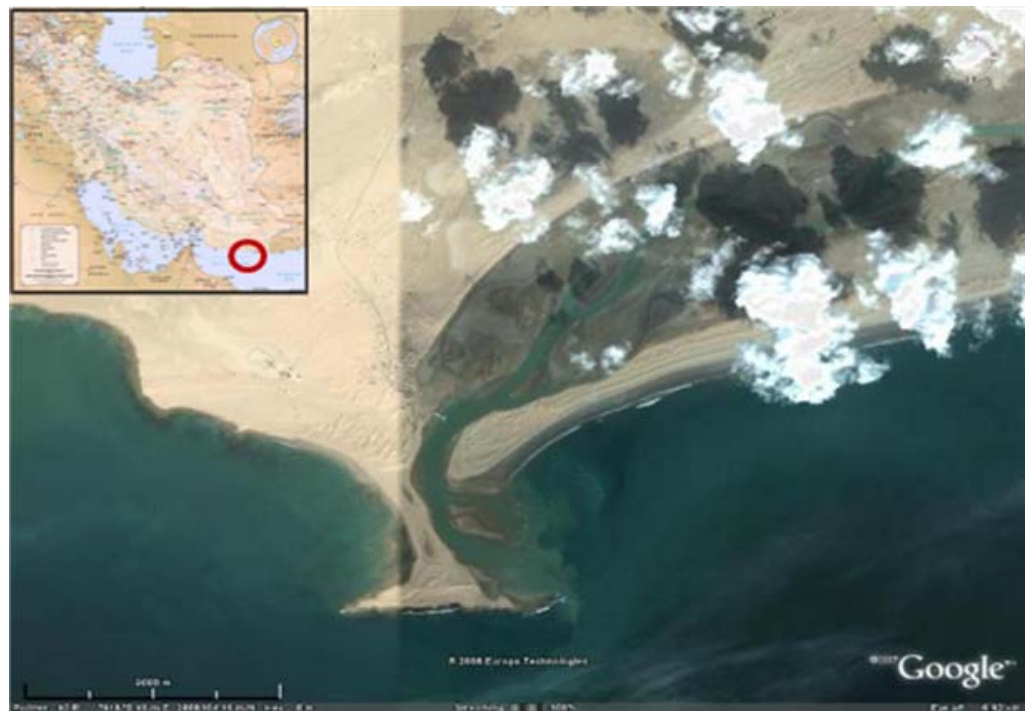

Figure 1. Location of Tang inlet.

\footnotetext{
${ }^{1}$ Daryabandar Consulting Engineers, No. 9, Kaj lane, Zabeti St., Heravi Sq., Pasdaran, Tehran 16677, Iran.
} 
Moreover, Tang estuary lies on riverine remains of a major flood channel of the region experiencing considerable floods during rare but intense rainy periods. More recently, within the last two years, the new climatic development of two tropical cyclones, Gonu and Phet, reaching this region, whereas in all past records spanning more than a hundred years it occurred just once about a century ago that one such cyclone ever happened to reach such high latitudes, implies that additional rain and sediment loads due to the more northerly tracks of tropical cyclones at the Monsoon season may in the future have altering effects on the existing inlet dynamics. During the dry season which is most of the time for this arid climate, due to the lack of fresh water the back-bay becomes a merely lagoonal system. However, the sediment influx due to flood currents, and increasingly in the future ushered in by the modified monsoonal cyclone tracks, is an issue to be taken into account in the study of the ephemeral morphology changes because of the relatively vast pertinent quantities.

Of particular interest is a reef acting as a natural offshore breakwater, leading to generation of tombolo/salient and partial obstruction of the longshore sediment transport. Anchoring of the inlet by a rock formation implies significantly reduced local wave action due to combined diffraction and refraction near the inlet, rendering it a Tide-dominated rather than a Wave-dominated system, where per Darlymple, Zaitlin and Boyd (1996), the estuary becomes longer as the coastal zone gradient decreases and the tidal range increases.

Another feature of the system is the existence of sand dunes along the back-bay contributing to sediment supply by the currents. In some parts notably near the inlet mouth, however, natural marsh vegetation has led to reducing the dunes contribution to wind-blown sediment transport.

In general, to trace the morphological evolution of such deltas, a.k.a. shoals, one has to have sufficient knowledge of sedimentation due to ebb and flood currents, as well as the re-working, transport and deposition by marine process. However, on a grand scale, gross deltaic shape is a function of the receiving basin geometry, regional tectonic stability, rates of subsidence due to compaction of newly deposited sediment and rate of sea-level rise which may play a major role in some cases.

For this Meso-tidal, inlet fronted by the offshore island rock, it is clear that inlet tidal currents significantly exceed the effects of longshore currents due to waves after their combined refraction \& diffraction at such a site. Therefore, according to Oertel (1988), it is expected that the ebb-tidal shoal is comprised of a well-defined ebb channel margin linear bars and terminal lobe with relatively smaller swash bars. This indeed is the case from geo-morphological analysis of the existing shoal data. Another feature is that because at Tang the inlet currents usually exceed the longshore currents, therefore the ebb-tidal shoal has become a relatively narrow and protruding one into the sea.

The bathymetry of the Tang bay also suggests that a tidal velocity asymmetry through the inlet gorge has resulted in greater sea-ward-directed transport through the inlet than the landward load, leading to relatively insignificant flood-tidal delta features inside the bay.

As Walton \& Adam (1976) stated, a change in the Tidal prism, through for example new structures, leads to a corresponding change in the volume of the Ebb-tidal shoal and thereby the sediment budget of nearby beaches. This point is important as a fishery pier's construction a few years ago has altered the ebb-tidal regime within the bay.

As far as the earlier study of the aerial and satellite imagery aided littoral sand transport computations show, the coastal area adjacent to the inlet has been in dynamic equilibration with relatively mild actual net transport compared to other Gulf of Oman sites, where a portion of the littoral sand transport naturally bypasses the inlet due to the shallow bathymetry and water depth contours of less than 2(m) in front of the rock formation.

In general, Tang Inlet may be classified as an ebb-tidal delta breaching type of unstable inlet following Fitzgerald (1988), where the position of throat is fairly stable despite a migration of the main ebb-tidal channel over the ebb delta, due in part to the protection by the rock formation from most of the local wave action (Fig. 2). This behavior often implies channel deflection and breaching caused by cut-bank erosion and subsequent landward bar migration leading to bar welding due to overwash processes closing off the initial channel path, as described further in continuation of this paper. The return period for shifting the position of inlet throat to one of the two set locations is approximately 10 to 15 years.

Even though, the related phenomena depend on the relative effects of tidal-prism, wave-action and backbay geometry as well as geological aspects, at times by dredging the gorge of any such inlet down to resistant sediments some stabilization may be reached. In this particular example, construction of a future dam to contain sediment load via floods would also restrict the migration potential. 


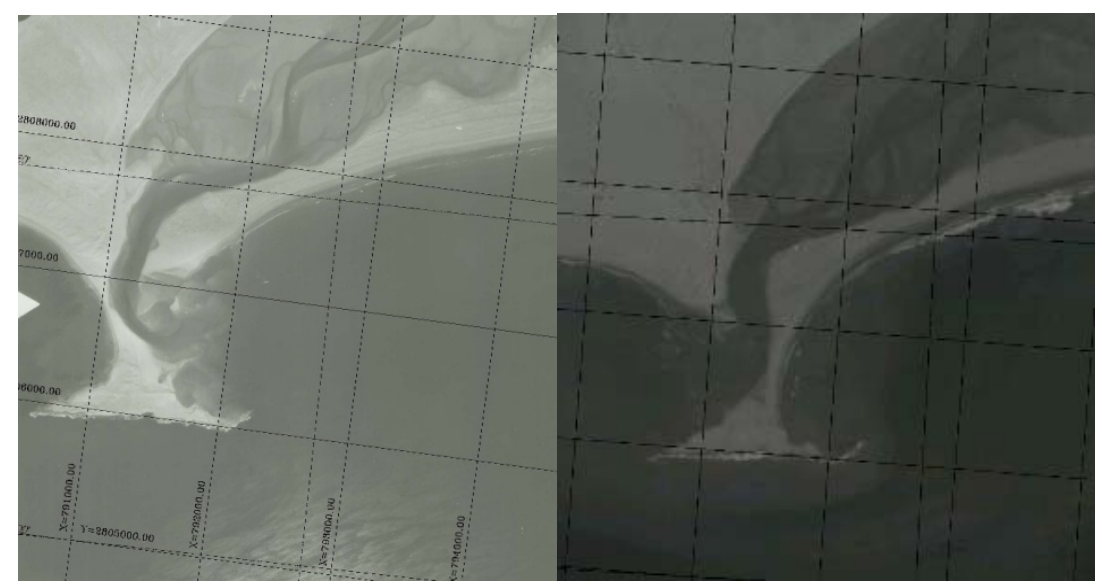

Figure 2. Inlet throat migration. Satellite images from 1966 (left) and 1995 (right).

\section{SITE MONITORING}

The site monitoring, utilized for calibration and verification of numerical modeling, was performed in two manners, namely, via a shoreline evolution study for the outside and a sedimentation pattern comparison inside the bay.

\section{Shoreline Evolution Study Outside the Bay}

Shoreline evolution study was accomplished by comparison of shoreline changes over the span of forty years in four intervals, taken from satellite images from 1966 to 2009. The data were subsequently transferred and geo-referenced within the Arc GIS environment, using UTM WGS84 coordinate system. Thus, shoreline changes after each time interval was derived and the respective erosion/accretion areas were calculated, as presented in Table 1, as follows.

\begin{tabular}{|c|c|c|}
\hline \multicolumn{3}{|c|}{ Table 1: Shoreline erosion/accretion areas outside of bay from 1966 to 2009.} \\
\hline Time interval & Erosion area $\left(\mathrm{m}^{2}\right)$ & Deposition area $\left(\mathrm{m}^{2}\right)$ \\
\hline $1966-1985$ & 2406000 & 884000 \\
$1985-2003$ & 810000 & 1345000 \\
$2003-2009$ & 483000 & 71700 \\
\hline
\end{tabular}

\section{Sedimentation Pattern Comparison inside the Bay}

Another complimentary monitoring study has incorporated three sets of hydrographical charts of the Tang lagoonal inlet system and its vicinity surveyed at 1993, 2000 and 2009. The following accounts analyses of the changes as encapsulated in the historical hydrographical charts in the light of complimentary undertaken sediment transport and morphological evolution studies. Based on the rather limited available site information, according to the 1993 survey the inlet channel was facing westward while the 2000 sounding pertains to time just after a relocation of the channel toward east. Until now, the inlet opening still keeps its eastward direction.

Channel migration from 1993 to 2000. According to Fig. 3, it is apparent that a blockage or selfsuffocation of the channel by virtue of the presence of the anchoring rock formation seems to be the predominant factor why the channel cannot maintain this orientation.

It deserves mention that both possible eastward and westward channel layouts align themselves during their quasi-stable operational term in a manner for their sediments not to be directly blocked by the presence of the rock body resulting in a curved channel shape. Moreover, absence of considerable wave energy implies that the ebb jet may now lead to a longer than otherwise channel which carries off a portion of its load to feed the outside littoral transport demands.

While the deposition of sediment load due to ebb-currents and rainy season floods has a lot to do with the pattern of Fig. 3, gradually blocking the channel path of 1993, another seemingly less significant factor governing the evolution is the mild growth of the western inlet spit due to the salient making potential of the rock formation causing a swash bar movement toward that spit. 


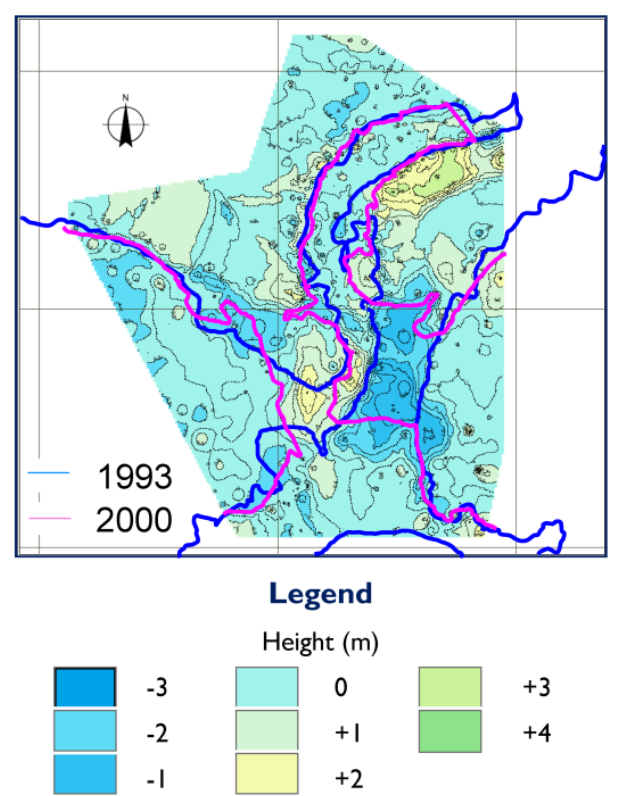

Figure 3. Sedimentation pattern inside the bay, from 1993 to 2000 based hydrographical charts.

The gradual increased hydraulic resistance to the currents in the channel favors the creation of competing spill-over channels and it does seem that one may have been formed north of the accretion area in the initial channel path where this spill-over channel together with action of diffracted waves on moving the swash bars shore-side has caused around $1 \mathrm{~m}$ of erosion, near the western shoreline.

Nonetheless, hydraulic considerations imply that such a shore-parallel channel is inefficient and thus non-sustainable. As a result, a breach of the delta to the east of channel occurs to provide a more direct route.

Overall, the inlet dynamics for this transition seems to be governed mainly by the ebb and rainy season flood loads being blocked and causing the need for a substitute path.

Other phenomena such as littoral sand transport which is relatively mild and pointing away from the inlet after partial bypassing the rock formation are not of a significant role; however the littoral transport in front of the rocky frontal region exists even though it does not interplay noticeably in the dynamics of the channel migration. Per Fig. 4, it therefore is the sediment due to the tides and floods which amount to around $170,000 \mathrm{~m}^{3}$ (i.e. $24,000 \mathrm{~m}^{3} / \mathrm{yr}$.) to block the initial path. To the east of this initial path, the fairly large area which has experienced erosion after the channel migration may indicate that initially other eastern spill-over channels than the main eastward channel were at play prior to the quasi-stabilization of the new eastern orientation of the channel. Having said that, it does seem that the eroded volume is rather large, being around 230,000 $\mathrm{m}^{3}$ according to Fig. 4, in the course of the channel moving from west to face the east. This figure deduced via past surveys, may possibly be actually much less due to the inherent errors in the fairly old soundings techniques, as well as the related measurement resolution and accuracy issues.

Judging by the topography data, it does seem that a shore-ward transfer of sand from the eastern shores adjacent to the Tang estuary caused by the northerly winds has caused dunes movement to the mid up to the ending northern parts of the estuary. It is hereby conjectured that a possible source of sediments in the ebb-tidal delta can be the sand blown-away by wind to the upper parts of the estuary.

From an engineering perspective, as related to the context of plans for a future fishing port in the area, these loose sand movements may be stabilized by vegetation such as using marsh guns in case the source of the delta development may need to be contained.

Notably, the geometry of the back-bay has experienced some change leading to changing tidal current speeds; however, the inaccuracies of the available measurement data, especially given the incompleteness of the surveyed areas just spanning the part of the bay near the shore and not the whole area, make a firm conclusion in this regard rather hard at the present stage.

In conclusion, it does seem that stabilizing the western channel of 1993 is rather complicated because of the above reasons and the geometry of the rock formation critically limits the possible modification of this route after accretion in the channel. 


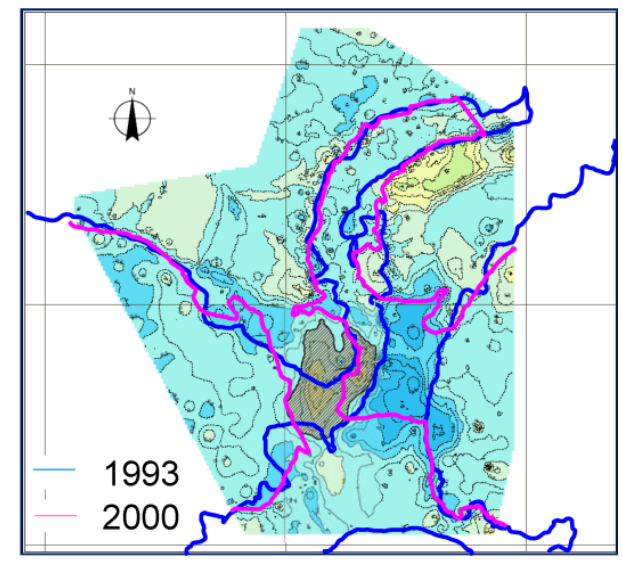

Legend

Height (m)

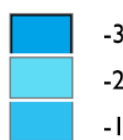

0
+1
+2

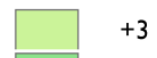

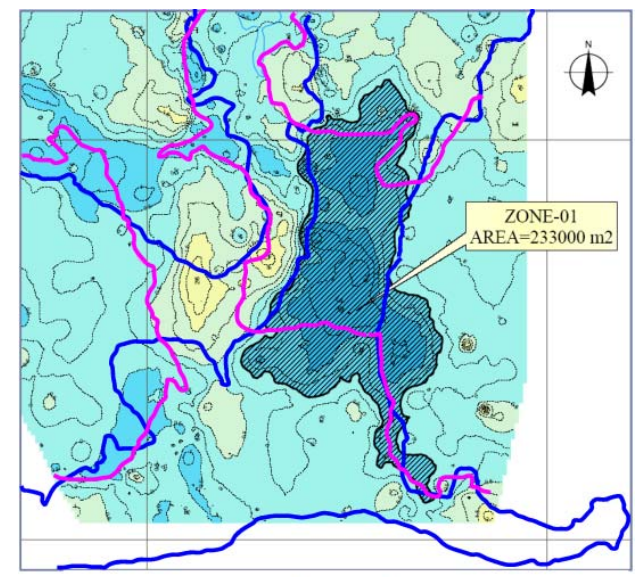

1993

Legend

2000

Height (m)
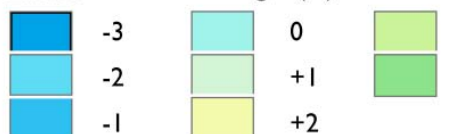

$+3$

$+4$

Figure 4. Erosion (right) and accretion (left) areas in the time interval between 1993 and 2000.

Sedimentation pattern comparison from 2000 to 2009. As could be observed in Fig. 5, Tang estuary has experienced the following alterations to its natural state in the last decade:

- Construction of a T-shaped jetty berthing structure in 2004 which initially blocked some sediments leading also to a narrowing of the estuary at jetty's location, ushering in a gradual erosion of the opposite side estuary banks because of increased local velocities. This has contributed to a delay in the natural period of Tang ebb channel migration.

- Dredging performed in 2006, while affecting the tidal prism and current velocities, may have possibly reached at some parts rocky or resistant sediments which cannot be carried out by ebbcurrents and ephemeral floods to the ebb shoal. This factor has also aided to the slowing rate of channel migration.

- Some back-bay areas toward the northern end part of the bay seem to have been filled in part due either to wind action or local community activities resulting in potentially a reduced tidal prism.

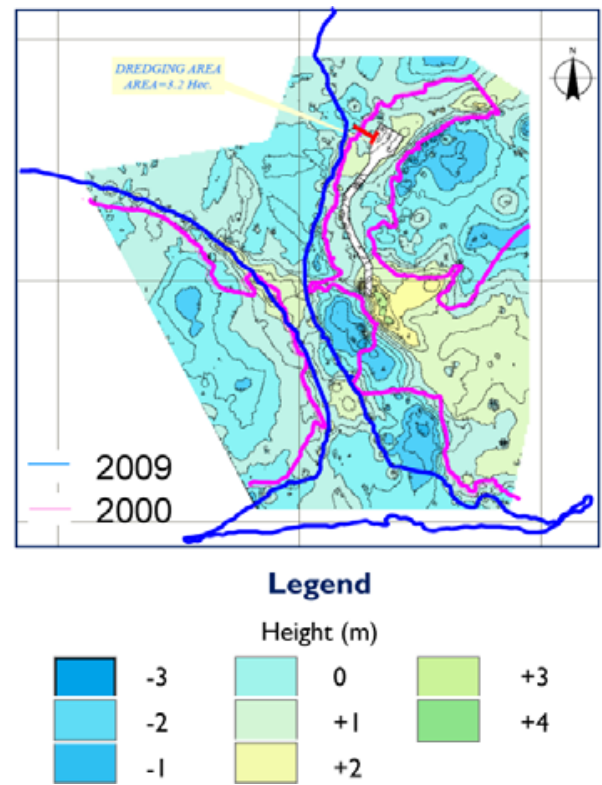

Figure 5. Sedimentation pattern inside the bay, from 2000 to 2009 based hydrographical charts. 
A deepening of the eastern ebb-tidal channel simultaneous with its narrowing is observed attributable to the growing spit located east of the inlet mouth. The growth of the spit has much to do with the diffraction currents after the Monsoon season waves meet the rock body, also referred to as the salient formation potential of the shore anchoring rock. However, not only the diffraction currents by themselves, but also the effects of the localized waves and current interactions, including possible wave shoaling prior to breaking not due to bathymetry alone but also the effect of head-on currents from the inlet help accentuate the buildup of the eastern inlet mouth spit. At the location of the existing T-jetty inside of the inlet, the constriction of the flow by the impermeable jetty has resulted in an erosion of the opposing banks of the inner channel moving the inner back-bay somewhat eastward.

On the western spit of the tidal inlet, as elucidated in Fig. 5, a relatively mild sedimentation pattern occurs which was also observed in the 1993 to 2000 transition of Fig. 3. Again, this seems to be due to diffraction currents and swash bars shoreward movements. In total, perhaps conservatively due to the inaccuracy of the soundings, around $80,000 \mathrm{~m}^{3}$, or $9,000 \mathrm{~m}^{3} / \mathrm{yr}$ is deposited according to Fig. 6a on the western side of the western ebb-tidal bars of the present channel. This is, as expected, notably less than the $24,000 \mathrm{~m}^{3} / \mathrm{yr}$ when the ebb load as well as the flood load is adding onto the wave load.

Some accretion toward the western end of the ebb-channel occurs which may mark the deposition of the ebb-tidal \& flood season sediments, in effect growing the westerns ebb-tidal bars of the eastern channel. This occurrence at the same time that the eastern spit is extending to narrow the channel implies that the western banks of the sediment body linking the rock formation to shore can potentially be breached by the cut-bank erosion due to the obliqueness of the channel and higher velocities due to narrowing of the channel at both sides due to the growing spit (i.e. diffracted wave action) and the lesser effect of the ebb-tidal \& flood deposition. Sedimentation on and around the eastern ebb-tidal channel bars, is approximated to be about $35,000 \mathrm{~m}^{3} / \mathrm{yr}$, which seems likely to be due to the growing swash bar (see Fig. 6b).

A point of concern as a possible anomaly in the survey data is the disappearance of the dune system along the eastern banks of the inner estuary which may have to do with the fact that the eastern oriented channel plausibly leads to a different, more away from shore sedimentation pattern than when this wave-current interaction is absent due to the west-facing channel where all Monsoonal waves are virtually fully blocked. If the currents do not lead to shoaling, blockage and breakage of the diffracted waves, then the more classical salient patterns at the shore, easily prone to transport by wind, after drying up in this hot climate with semi-diurnal tides, may feed the migration of lose sand dunes load eventually back into the inlet channel.

The eastern channel, according to Fig. 6c, has eroded by more than $250,000 \mathrm{~m}^{3}$ or $30,000 \mathrm{~m}^{3} / \mathrm{yr}$, in part aiding the growth of the eastern accretion pattern and the rest being carried away by the outside littoral currents, either to the east or in front of the rock formation away toward the west.
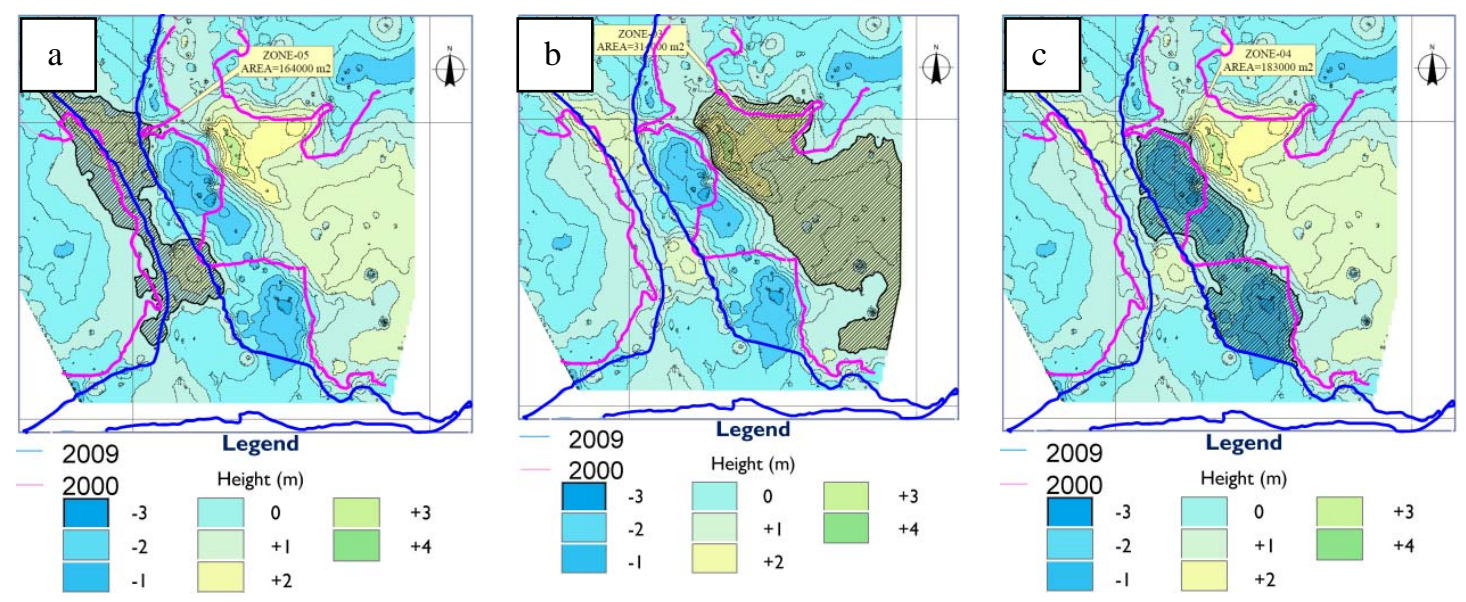

Figure 6. Erosion and accretion areas in the time interval between 2000 and 2009: (a) Accretion area westward of the natural reef; (b) Accretion area eastward of the natural reef; and (c) Erosion area eastward of the natural reef.

In conclusion, the underlying cause of somewhat slowed-down mechanism of the eastern oriented channel re-migrating to revert back to the 1993 west-facing channel seems to be in a nutshell that the growing eastern spit and the deposition of ebb and floods loads west of the present channel collaborate 
to cause the oblique channel to cut its narrow western bank to find a hydraulically advantageous shorter route which can also be aided by the breaching from outside effects of the seldom occurring intense waves in the non-Monsoonal season. As discussed earlier, such a western orientation would remain preferred until the sediment load from inside the bay blocked by the fronting rock would force the channel to deflect again by the breach of eastern banks of the west-facing channel in an on-going cycle for as long as the underlying factors contributions are not changed severely be natural climatic changes or man-made intervention.

\section{NUMERICAL MODELING}

\section{Deepwater Wave Climate}

The morphological and hydrodynamic modeling of the aforementioned inlet was performed, using MIKE Zero software package. For offshore wave climate, Hindcast results from the Iranian Seas Wave Modeling (ISWM) project were incorporated in the present study. In short, wind data from the European Centre for Medium-Range Weather Forecasts (ECMWF), lasting for over an eleven years period along Iranian coastal waters, were used to drive the Mike21 SW spectral wave generation and propagation model with the modeling, calibration and verification methodology, as described by Golshani et. al. (2007) for the Caspian Sea region.

The hindcast related deep-water wave-rose is presented in Fig. 7. Notably, the wave climate is seen to be fairly mild in this region with the predominant direction of waves from SSE Monsoon direction.

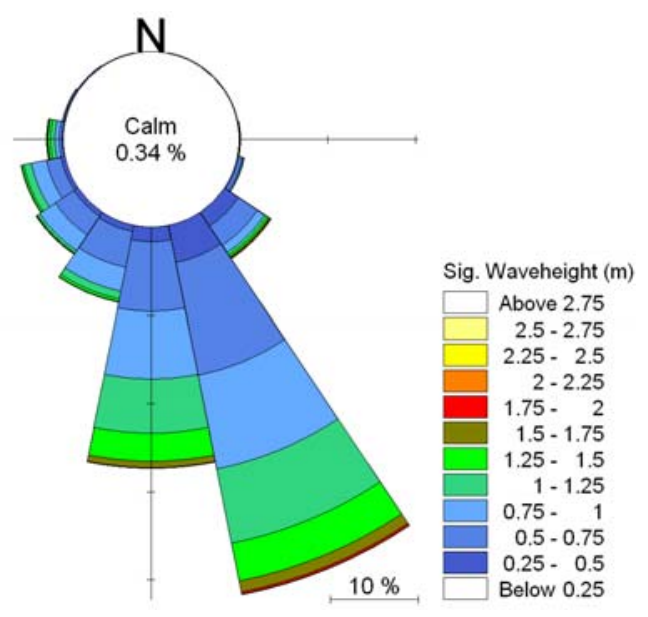

Figure 7. ECMWF-based deepwater wave-rose for Tang region.

In order to correlate the significant waveheight and mean wave period, $T_{02}$, a regression analysis was performed for ISWM wave data leading to the following equation for wind-generated waves:

$$
T_{02}=0.22+3.34\left(\frac{H_{s}}{g}\right)^{1 / 2}
$$

Where $H_{s}$ is the significant wave height. For the case of swells, no proper correlation was found, however, the main wave energy at this site is due to Monsoon swells and more recently waves generated by the tropical storms with northbound trajectories from the Indian Ocean.

\section{Nearshore Wave Transformations}

After deriving the extreme offshore wave conditions, the nearshore wave transformations are modeled using the Mike 21 PMS model which is based on the parabolic approximation to the elliptic mild-slope equation. As for the model set-up, the offshore boundary conditions of wave height, period and mean wave direction are provided by the afore-mentioned hindcast wave characteristics modeling. Symmetrical lateral boundary conditions were enforced, with the extent of the model being defined in a manner that waves propagate into the region of interest from the offshore boundary and all features of main interest for interpretation of results are kept reasonably away from the lateral boundaries. Regarding the design water level for those simulations related to a future fishery port, a value of $1.6 \mathrm{~m}$ with respect to the chart datum was used in all the presented simulations as the Mean Sea Level value. 
Additionally, it proves imperative to set up a high resolution discretization grid to properly resolve the localized effects of the bathymetry on the nearshore wave characteristics. The wave model was run both with the conventional fairly coarse- yet within the realms of the typical acceptable spatial discretization range of the model-, as well as the necessary finer resolution scenarios, with the results being quite different particularly around the natural reef, confirming the need for proper resolution of bathymetry to obtain an apposite number of points per wavelength after discretization. For final simulations, a spatial resolution of $5 \times 5 \mathrm{~m}$ was selected as at this resolution the natural rock formation and related bathymetry related refraction-diffraction patterns were sufficiently captured.

Wave-breaking was also incorporated, also for estimating wave-driven currents related to sediment transport characterization of the site. For this purpose, the formula of Battjes and Janssen (1978) was employed by taking the default parameter values as recommended in the user manual of the model. As for the model solution method, a Pade type approximation was incorporated. The bed roughness representing bottom friction was considered as a calibration parameter. The model was run for all contributing wave-directions, extending from east to west, in seven intervals of 22.5 degrees. The simulation result from the dominant SE direction is presented in Fig. 8. Evidently, various proposed new fishery port layouts are overlaid on the simulation result so that wave characteristics next to breakwaters for each layout could be determined and further used for site selection and preliminary design purposes.

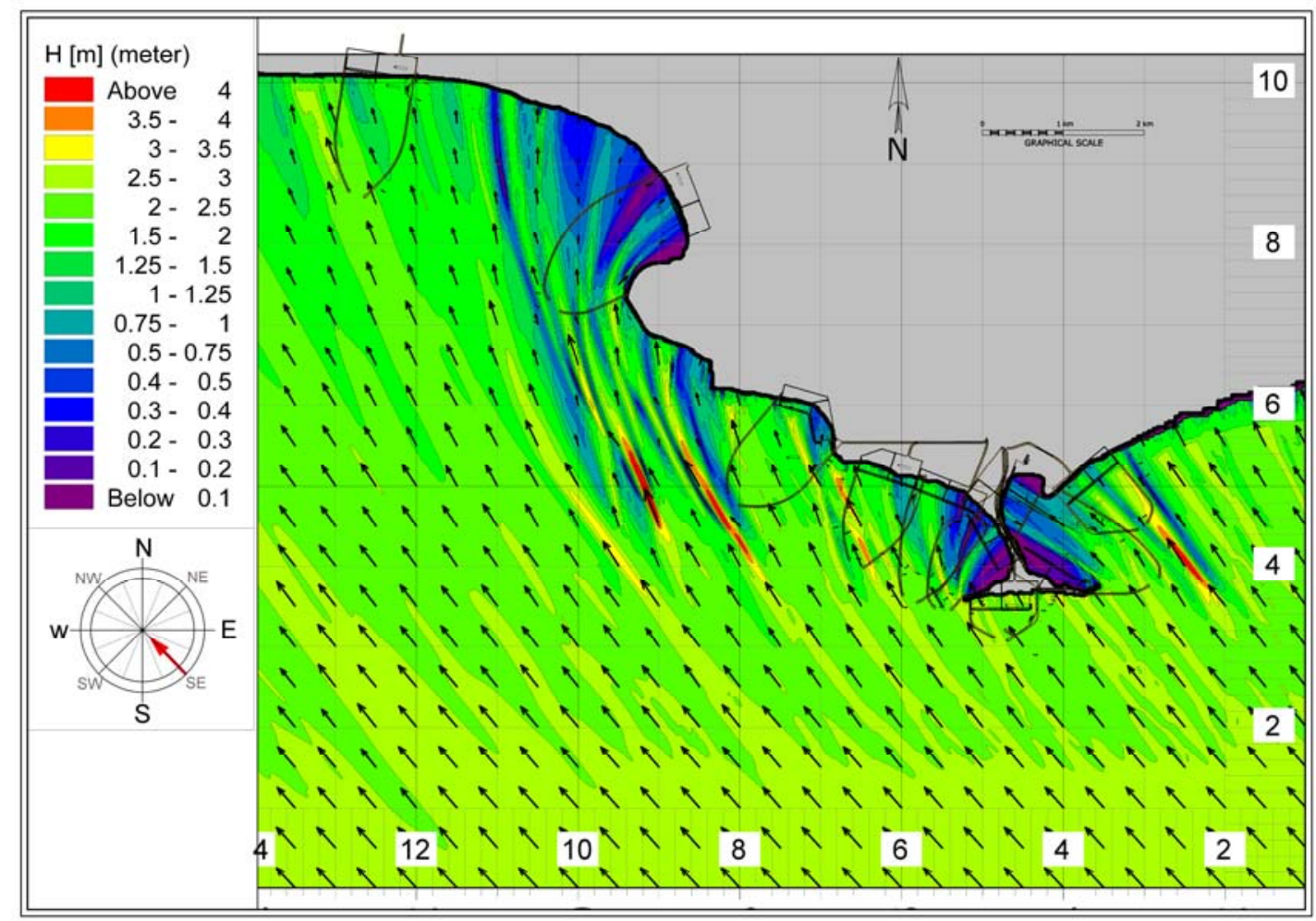

Figure 8. PMS wave transformation modeling result for SE wave direction.

Moreover, the wave transformation modeling was performed for both before and after scenarios for each of the proposed port layouts so that the effect of port on the adjacent coastal morphology could be properly understood in sediment transport modeling (See Fig. 9).

\section{Coastline Evolution Modeling}

For coastline evolution, the one-line model provided by LITPACK module of Mike Zero was employed. Longshore current and littoral drift along the coast were calculated by LITDRIFT engine of LITPACK model for thirty four cross-sections covering fifteen kilometers of coastline. Laboratory analysis of in-situ collected sediment samples for ten points inside and outside of the bay determined the sediment parameters, which indicate a sandy bed around and eastward of the rock formation and a cap-rock bed westward of the natural reef. No ambient current or wind was incorporated in the initial 
modeling. For calculation of wave motion outside the boundary layer, the semi-empirical Doering and Bowen (1995) approach was incorporated which is valid for all depths and both breaking and nonbreaking types of waves. Moreover, the effect of streaming was taken into account by including convective terms in the solution method. The bed concentration was determined by a deterministic approach in all of the simulations. As per other parameters, the default values recommended by LITPACK model were employed. Sediment roses obtained for five sample points are presented in Fig. 10, indicating most dominant transport direction being from South-Easterly sector.
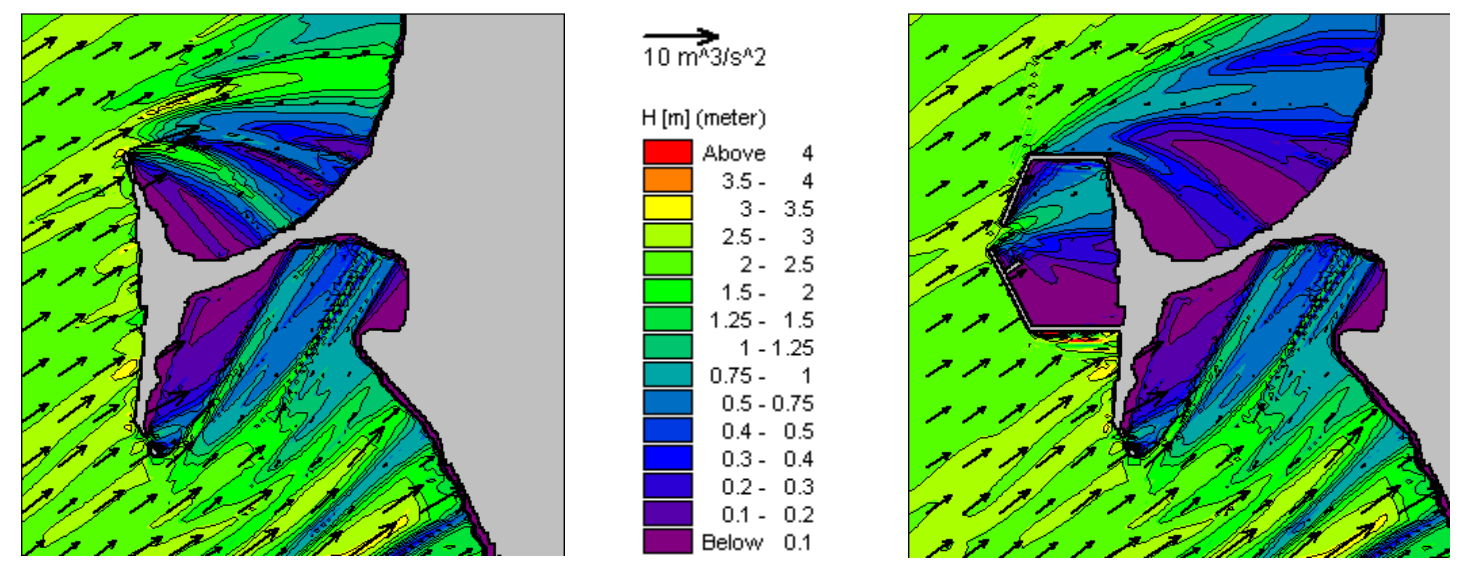

Figure 9. PMS wave transformation modeling result for SE wave direction around the natural reef for both cases of including and excluding port layout.

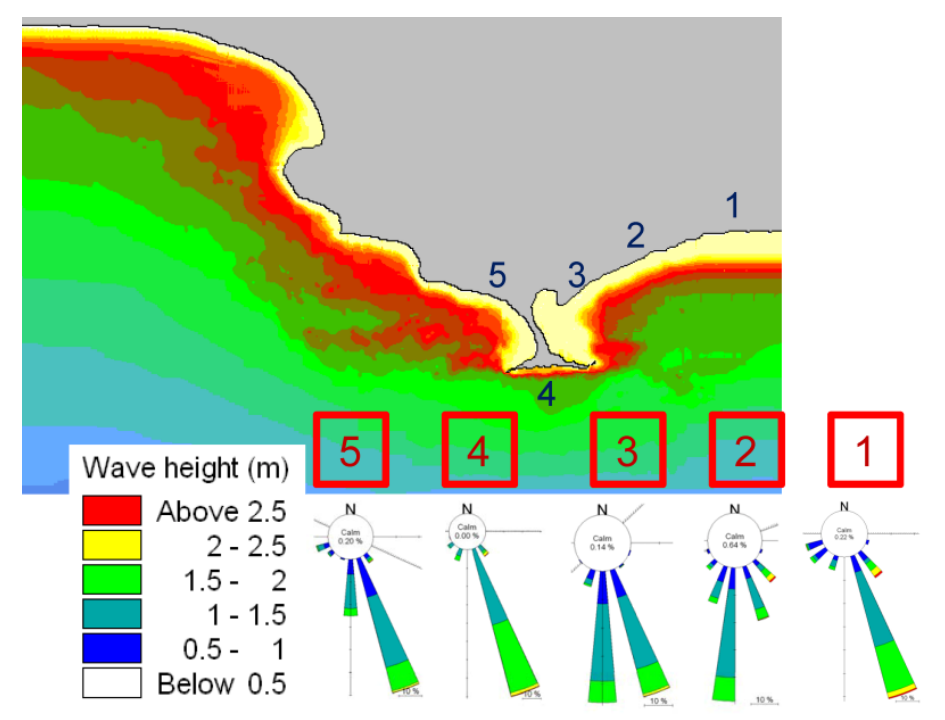

Fig. 10. Sediment-rose plot for five points along the coast.

Another point as evident from both LITPACK and Kamphuis formula calculations is the occurrence of a converging type of Null-point somewhere to the east of the inlet where the net sand transport direction reverses. The exact position of the Null-point varies in time mainly due to waveclimate. In brief, the inlet is at a location where to its east the littoral transport is eastwards till the Nullpoint where it reverts to westward, whereas west of the inlet the littoral transport is also westward and stronger. Fig. 11 shows two sample cross-sections and their pertinent annual accumulated net littoral drift, where change in annual drift sign asserts the occurrence of a Null-point somewhere between these two points. Nevertheless, looking at the shoreline trend eastward of the bay, where no localized shoreline convex pattern due to occurrence of a Null-point is vividly observed, it could be deduced that the entire calculated potential annual drift will not be actualized in the region of study. 

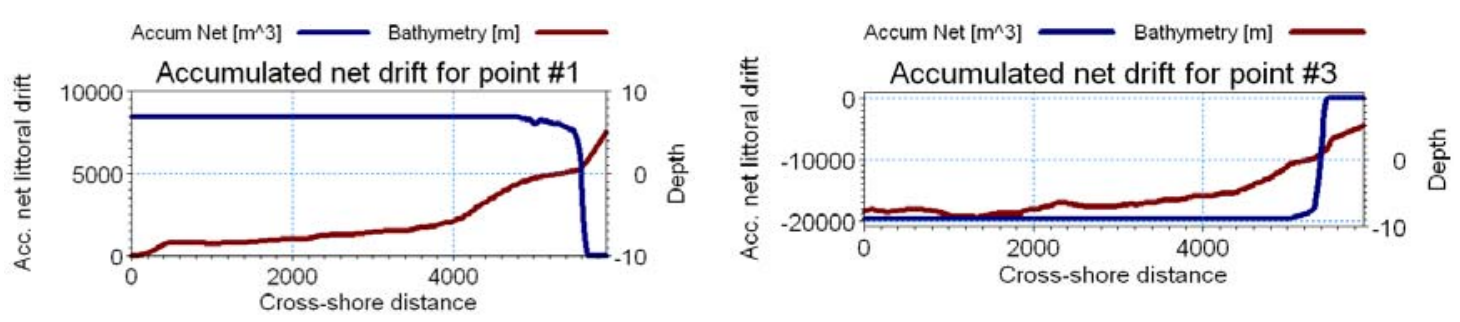

Figure 11. Accumulated net annual littoral drift plot for two sample cross-sections.

Furthermore, the shoreline evolution was modeled using the one-line morphological module of LITPACK known as LITLINE. The effect of current and sedimentation from the bay were included as a source term in the model in complimentary model runs. Annual sediment yield potential from Tang watershed is estimated to be between 44000 and $74000 \mathrm{~m}^{3} / \mathrm{yr}$, the maximum of which was incorporated in the one-line model rather conservatively. The height of active beach was considered to be $3 \mathrm{~m}$. Moreover, the presence of the natural breakwater was simulated. For solution parameters, the recommended default values of LITLINE were chosen. The coastline evolution for a time span of forty years, considered as fishery port's lifetime, was modeled and is presented in Fig. 12. Apart from sedimentation around the eastern ebb-tidal channel bar no distinct change in coastline is observed, which attest observations from satellite images concerning dynamic equilibrium of the beach on the one hand, and an explanation for the westward delta breaching of the channel on the other.

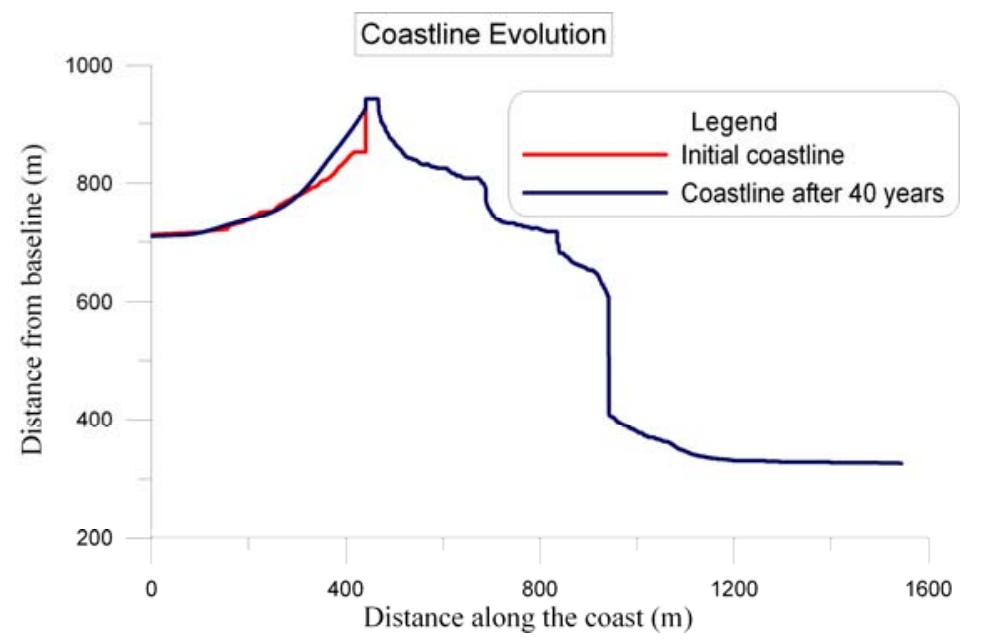

Figure 12. Coastline evolution in Tang region over the time-span of 40 years.

\section{Bay Tidal and Sediment Transport Modeling}

In order to simulate sediment transport inside the bay and at the inlet, modeling of the tidal exchange and currents is required, which was performed using MIKE 21 Flow model. As for the model set-up, bathymetry of inside of the bay was taken from a hydrographical survey conducted in 2000 and comparison of satellite images. Boundary conditions were enforced by incorporating a month long tidal measurement at a point located on the opening of the bay using a tide-gauge. Fig. 13 depicts the domain of numerical modeling as well as the monthly tidal water level measurements behind the rock formation.

Wave radiation stresses, used for modeling of the present case where combined interaction of waves and tidal current are at play, were taken from afore-mentioned PMS wave transformation modeling. Moreover, velocity-based eddy viscosity values were dynamically calculated by means of the Smagorinsky formula, using the proportionality factor of 0.5 for each area. For the initial water level elevation, a constant Mean Sea Level value was set for the entire modeling domain. The effect of flood and dry was incorporated as well as the bed resistance parameter with the latter being considered as a calibration parameter. Fig. 14 shows sample current field results for both flood and ebb periods. Maximum velocity in the flood half-cycle occurs in the inlet throat that is in conformity with site 
monitoring of the eroded area as presented in Fig. 6c. As for the ebb half-cycle, numerical modeling results show two regions for the occurrence of maximum current velocity, one located at inlet throat and the other at the opening of the eastern channel that agrees well with observations as explained in site monitoring section. Moreover, it is observed that the value for maximum velocity exceeds $1 \mathrm{~m} / \mathrm{s}$ which is required to prevent the closure of the inlet system (Escoffier 1940).
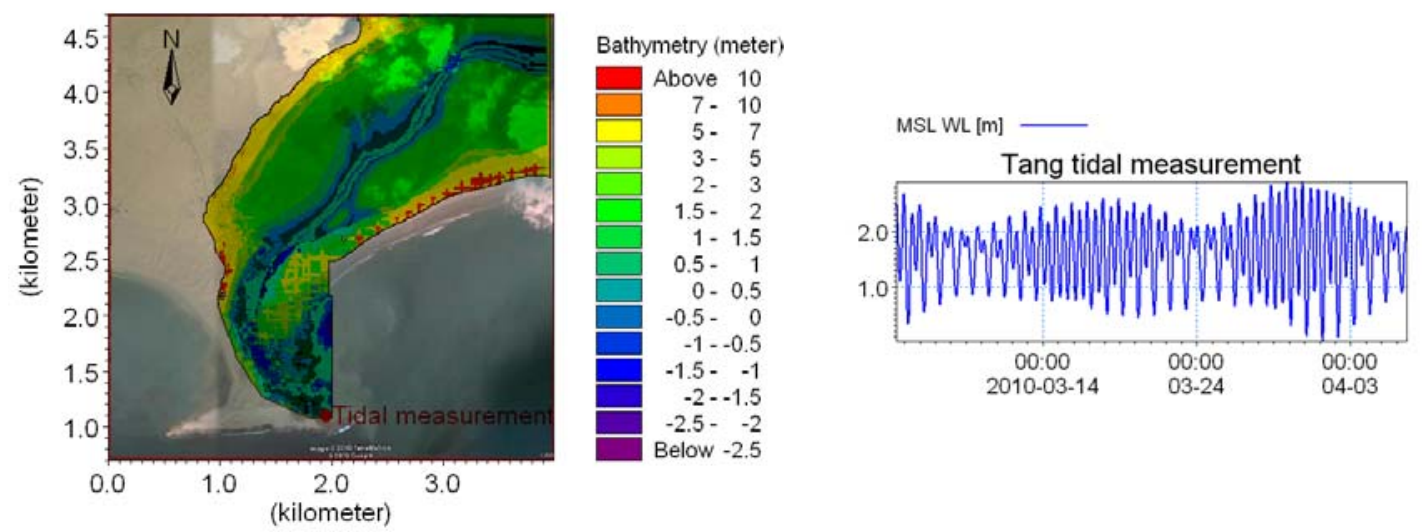

Figure 13. Numerical modeling domain for tidal simulation (left) and one month tidal measurements at boundary of the domain (right).
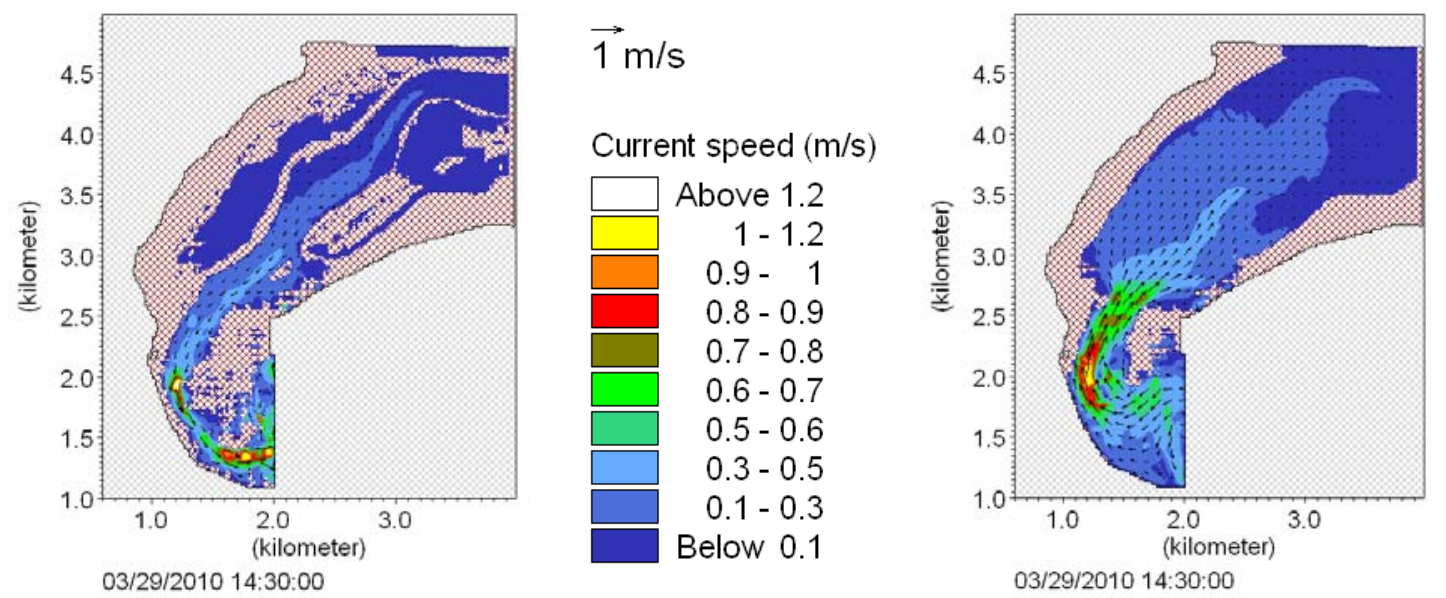

Figure 14. A sample numerical modeling current field result for both flood (right) and ebb (left) periods.

The sediment transport modeling inside the bay is performed employing MIKE 21 Non-Cohesive Sediment Transport Model. Hydrodynamic input data was incorporated from an output file obtained from MIKE 21 Flow simulation. As for calculating sediment transport under combined wave and current condition, direct computation of total load using Bijker formula was selected. Sediment properties such as grain size diameter and relative density of the sediments were taken from in situ measurements. For other values such as wave breaking parameters, the default values recommended by MIKE 21 were applied. Bijker transport coefficient was considered as a calibration parameter. Transport capacities for a sample flood and ebb event is presented in Fig. 15. Numerical modeling results give the maximum capacity during the ebb currents which is supported by site monitoring observations (Fig. 6c). It is also evident that the western end of the ebb-channel is prone to sedimentation that is in conformity with monitored accretion in the same area as shown in Fig. $6 \mathrm{~b}$. 

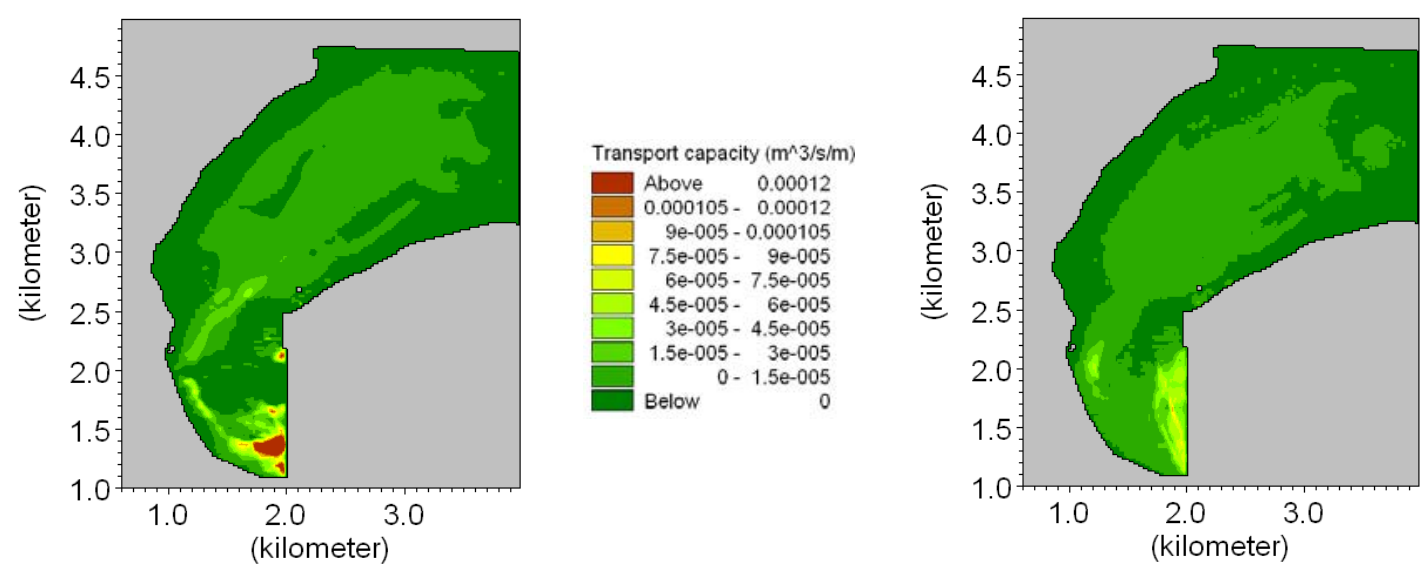

Figure 15. Transport capacity rates for flood (right) and ebb (left) cases.

\section{CONCLUSIONS}

A rare case of a cyclic migrating inlet with two quasi-stable ebb tidal eastern and western channels, sheltered behind a natural offshore rock formation is studied. A site monitoring study utilizing past aerial, satellite and hydrographical survey data was conducted for tracing both adjacent shoreline evolution as well as the more localized sedimentation pattern around the natural reef and the immediate vicinity of the inlet. Subsequently, numerical modeling for the site of interest was undertaken using one-line modeling of the entire coastline as well as two-dimensional sedimentation simulation of inside the bay.

It is concluded that the switching from the westerly to easterly channel orientation is predominantly caused by floods and ebb-tidal sediment loads helped by the diffraction currents because of the rock body. The breaching starts off forming at least two competing spill-over channels where one is hydraulically more advantageous and is eventually preferred. The closure of the east-facing channel is mainly brought about by the diffraction currents due to Monsoon season southerly waves, with the sediment deposition from the inlet contributing also to some extent to the cut-bank erosion possibility of the western spit to disconnect the westward shore from the rock formation. Numerical modeling results conform satisfactorily with the site monitoring observations. Nonetheless, owing to the lack of accurate and comprehensive enough in-situ data the results of the present study are currently deemed tentative pending the completion of a sedimentology and hydrodynamic data acquisition campaign, as well as a complete hydrographical survey of rather long and narrow Tang bay

\section{ACKNOWLEDGMENTS}

The authors would like thank Mr. Hossein Siavashi for his valued assistance in ArcGIS analysis of the pertinent data for site monitoring study for Tang region.

\section{REFERENCES}

Battjes, J.A., and J.P.F.M. Janssen. 1978. Energy loss and set-up due to breaking of random waves, Proceedings of $14^{\text {th }}$ International Conference on Coastal Engineering, ASCE, 466-480.

Dalrymple, R. W., B. A. Zaitlin, and R. Boyd. 1992. Estuarine Facies Models: Conceptual Basis and Stratigraphic Implications, Journal of Sedimentary Petrology, 62(6), 1130-1146.

Doering, J.C., and A.J. Bowen. 1995. Parameterization of orbital velocity asymmetries of shoaling and breaking waves using bispectral analysis, Coastal Engineering, 26(1-2), 15-33.

Escoffier, F.F. 1940. The stability of tidal inlets, Shore and Beach, 8(4), 114-115.

FitzGerald, D.M., S. Penland, and D. Nummedal. 1984. Control of Barrier Island Shape by Inlet Sediment Bypassing: Ease Friesian Islands, West Germany, Marine Geology, 60, 355-376.

FitzGerald, D. M. 1988. Shoreline Erosional-Depositional Processes Associated with Tidal Inlets, Hydrodynamics and Sediment Dynamics of Tidal Inlets, Lecture Notes on Coastal and Estuarine Studies, D. G. Aubrey and L. Weishar, eds., 29, Springer-Verlag, New York, 186-225.

Golshani, A.; S. Taebi, and V. Chegini. 2007. Wave Hindcast and Extreme Value Analysis for the Southern Part of the Caspian Sea. Coastal Engineering Journal, 49(4), 443-459. 
Nummedal, D., and I.A. Fischer 1978. Process-Response Models for Depositional Shorelines: The German and the Georgia Bights, Proceedings of the $16^{\text {th }}$ Conference on Coastal Engineering, ASCE, 1215-1231.

Oertel, G.F. 1988. Processes of Sediment Exchange Between Tidal Inlets, Ebb Deltas, and Barrier Islands, Hydrodynamics and Sediment Dynamics of Tidal Inlets, Lecture Notes on Coastal and Estuarine Studies, 29, D. G. Aubrey and L. Weishar, eds., Springer-Verlag, New York, 297-318.

Walton, T.L., Jr., and W.D. Adams. 1976. Capacity of Inlet Outer Bars to Store Sand, Proceedings of the $15^{\text {th }}$ Coastal Engineering Conference, ASCE, 1919-1937. 